\title{
De vecinos sufrientes a ciudadanos peticionantes. Actores e instituciones en la construcción de un arte de curar moderno en la provincia de Santa Fe [Argentina, 1847-1907]
}

Resumen: El artículo analiza las transformaciones de las peticiones de salud durante la segunda mitad del siglo XIX en la provincia de Santa Fe [Argentina] para reflexionar sobre su construcción como demanda social. Con el estudio de expedientes administrativos de diversas localidades nos proponemos, en primer lugar, registrar la diversidad de actores que buscaban curar por fuera de la medicina diplomada y las estrategias de la población para conseguir su autorización. En segundo lugar, recuperar las representaciones y saberes que fundaban la comprensión de la enfermedad por parte de quienes demandaban atención en salud. Por último, analizar la mutación de sus apelaciones a un Estado provincial en construcción y su consecuente ciudadanización. Palabras clave: historia de la salud, historia de la medicina, pacientes, ciudadanos.

\section{From suffering neighbors to demanding citizens. Actors and institutions in the construction of a modern healing in the Santa Fe province [Argentina, 1847-1907]}

Abstract: The article analyzes changes in health requests during the second half of the 19th century in the province of Santa Fe [Argentina], focusing on the way these requests construct social demand. Based on administrative files from various localities, we first register the diversity of actors who sought to heal outside of graduate medicine and their strategies to obtain authorization. Secondly, we focus on the representations and knowledge related to the understanding of disease by those who demanded health care. Finally, we analyze changes in their appeals to a provincial state under construction and the consequent building of citizenship. Keywords: history of health, history of medicine, patients, citizens.

\section{De vizinhos sofredores a cidadãos peticionários. Atores e instituições na construção de uma moderna arte de curar na província de Santa Fé [Argentina, 1847-1907]}

Resumo: 0 artigo analisa as transformações das petições de saúde durante a segunda metade do século XIX na província de Santa Fé [Argentina] para refletir sobre sua construção como demanda social. Com o estudo de arquivos administrativos de várias localidades, pretendemos, em primeiro lugar, registrar a diversidade de atores que buscavam curar fora da medicina diplomada e as estratégias da população para obter sua autorização. Em segundo lugar, recuperar as representações e saberes que fundamentavam a compreensão da doença daqueles que demandavam atenção em saúde. Finalmente, analisar a transformação de suas demandas a um estado provincial em construção e a consequente formação de sua cidadania.

Palavras-chave: história da saúde, história da medicina, pacientes, cidadãos.

Cómo citar este artículo: José Ignacio Allevi y Adrián Carbonetti, “De vecinos sufrientes a ciudadanos peticionantes. Actores e instituciones en la construcción de un arte de curar moderno en la provincia de Santa Fe [Argentina, 1847-1907]", Trashumante. Revista Americana de Historia Social17 [2021]: 80-103.

DOI: 10.17533/udea.trahs.n17a04

Fecha de recepción: 20 de diciembre de 2019

Fecha de aprobación: 18 de agosto de 2020

José Ignacio Allevi: Doctor en Historia por la Universidad Nacional de la Plata, Argentina. Investigador asistente en el Consejo Nacional de Investigaciones Científicas y Técnicas [Conicet], profesor de la Universidad Nacional de Rosario. ORCID: 0000-0003-4819-1398.

Correo electrónico: joseignacio.allevi@gmail.com

Adrián Carbonetti: Doctor en Demografía por la Universidad Nacional de Córdoba, Argentina. Investigador Principal en el Consejo Nacional de Investigaciones Científicas y Técnicas [Conicet], profesor de la Universidad Nacional de Córdoba. ORCID: 0000-0002-2093-2046.

- Correo electrónico: acarbonetti@hotmail.com 


\section{De vecinos sufrientes a ciudadanos peticionantes. Actores e instituciones en la construcción de un arte de curar moderno en la provincia de Santa $\mathrm{Fe}$ [Argentina, 1847-1907]}

José Ignacio Allevi y Adrián Carbonetti

\section{Introducción}

Como parte de la ambiciosa agenda que la historia socio cultural de la salud y la enfermedad se ha dado en las últimas décadas en América Latina, un número de pesquisas en constante aumento puso en foco la miríada de prácticas, tradiciones y actores que intervenían en los procesos de cura durante el siglo XIX. ${ }^{1}$ Al restituir la centralidad que estas tenían, se iluminaron igualmente aspectos vinculados al ejercicio de la medicina académica en su afán por construir un espacio simbólico y reconocido en un campo de prácticas, en el cual era minoritaria su influencia. ${ }^{2}$ En efecto, el abanico de actores legítimos que componían la escena del arte de curar latinoamericano abarcaba desde sangradores y barberos hasta curanderos, médicos populares, boticarios, "charlatanes”, espiritistas o parteras, entre otros. ${ }^{3}$

1. María Silvia Di Liscia, "Reflexiones sobre la 'nueva historia social' de la salud y la enfermedad en Argentina", Historias de salud y enfermedad en América Latina, eds. Adrián Carbonetti y Ricardo González Leandri (Córdoba: Universidad Nacional de Córdoba, Centro de Estudios Avanzados, 2008) 15-47; Diego Armus, "Legados y tendencias en la historiografia sobre la enfermedad en América Latina moderna", Críticas e atuantes. Ciências sociais e humanas em saúde na América Latina, orgs. Maria Cecília de Souza Minayo y Carlos E. A. Coimbra Jr. (Río de Janeiro: Editora Fiocruz, 2005) 183-205.

2. Nikelen Acosta Witter, "Curar como Arte e Ofício: contribuições para um debate historiográfico sobre saúde, doença e cura", Tempo 19 (2005): 13-25.

3. María José Correa Gómez, "Por haber sanado a muchos y haber matado a varios. Charlatanes, practicantes y curanderos. La justicia y el ejercicio médico ilegal. Chile, 1874-1919”, Delincuentes, policías y justicias. América Latina, siglos XIX y XX, ed. Daniel Palma Alvarado (Santiago: Ediciones Universidad Alberto Hurtado, 2015) 466-490; Tânia Salgado Pimenta, "Physicians and Surgeons in the early decades of the nineteenth century in Brazil", Almanack 22 (2019): 88-119. DOI: 10.1590/2236-463320192204; Betânia Gonçalves Figueiredo, $A$ arte de curar. Cirurgiões, médicos, boticários e curandeiros no século XIX em Minas Gerais (Río de Janeiro:Vício de Leitura, 2002); Steven Palmer, "La voluntad radiante del Profesor Carbell. Medicina popular y populismo médico en Costa Rica en el decenio de 1930", Entre médicos y curanderos. Cultura, historia y enfermedad en la América Latina moderna, ed. Diego Armus (Buenos Aires: Grupo Editorial Norma, 2002) 
Sin embargo, en este proficuo registro la figura de las y los actores que requerían cuidados médicos aún es poco explorada. En este trabajo nos interesa atender a la participación de vecinas y vecinos en diversos reclamos por condiciones de salud con la intención de reflexionar sobre algunas cuestiones: a qué "expertos" recurrían, las significaciones atribuidas a la enfermedad y su vínculo con el medio natural, el carácter colectivo de la experiencia de la enfermedad, así como también la progresiva construcción de sentidos en torno a la autoridad estatal en plena constitución.

La reflexión teórica e historiográfica en torno a este problema tiene varias décadas. Ya en 1985 Roy Porter convocó a una historia verdaderamente social de la medicina que incluyese otros actores más allá de los médicos y el Estado, que orientara la mirada hacia los sufferers. Con ello, el historiador inglés eludía usos anacrónicos del concepto de paciente, más acorde a sociedades modernizadas en las cuales el saber médico y sus expertos se encuentran legitimados, así como socialmente incorporada la jerarquía característica de tal vínculo. De esta manera, su reflexión apostaba por entender la experiencia de la enfermedad como un fenómeno colectivo antes que individual, que enfatizaba la necesidad de recuperar los contextos materiales y simbólicos de su emergencia, así como la plasticidad ínsita de la relación entre doliente y experto. ${ }^{4} \mathrm{Si}$ bien investigaciones sucedáneas se inscribieron en esta ambiciosa agenda, ${ }^{5}$ la apuesta de Porter resultó mayormente inconclusa en la pesquisa historiográfica, al tiempo que brindó pocas herramientas para pensar este objeto en sociedades coloniales, cuya modernidad resultaba periférica o tardía. ${ }^{6}$ En la exploración de la agencia de los dolientes — antes que en su "voz" misma- ${ }^{7}$ otros autores señalaron la dificultad de restituir efectivamente ese decir respecto a las mediatizaciones que los presentan en los documentos, a

259-292; Beatriz Teixeira Weber, As artes de curar: medicina, religião, magia e positivismo na República Rio-Grandense, 1889-1928 (Santa María: Editora da Universidade Federal de Santa Maria, 1999); Eliane Cristina Deckmann Fleck, "Sobre feitiços e ritos. Enfermidade e cura nas reduções jesuítico-guaranis (século 17)”, Varia Historia 21.33 (2005): 163-185; Claudia Agostoni, “Ofertas médicas, curanderos y la opinión pública: el Niño Fidencio en el México posrevolucionario", Anuario Colombiano de Historia Social y de la Cultura 45.1 (2018): 215-243. DOI: 10.15446/achsc. v45n1.67557.

4. Roy Porter, "The Patient's View: Doing Medical History from Below", Theory and Society 14.2 (1985): 175-198.

5. Edward Shorter, Doctors and their Patients. A Social History (New York: Simon and Schuster, 1985).

6. Entenderemos las transformaciones radicales que impactaron social, demográfica y materialmente el territorio argentino desde la segunda mitad del siglo XIX como una modernización tardía o periférica. Esto apunta a dos cuestiones propias de espacios otrora coloniales. Primero, la desigual temporalidad en la recepción y adopción de los desarrollos industriales y científicos del "centro", de acuerdo con la posición subordinada de estos en el sistema capitalista. En segundo término, la circulación de los saberes y prácticas de la medicina académica occidental en estos espacios debió dialogar y disputar posiciones con cosmovisiones y actores de larga inscripción.

7. David Armstrong, “The Patient's View”, Social Science and Medicine 18.9 (1984): 737-744. 
lo que se suma que los problemas metodológicos - y sobre todo teóricos - para captarla y sistematizarla no derivaron en resultados concluyentes. ${ }^{8}$

El estudio de este objeto en la historiografia argentina arroja escasas investigaciones. Se destacan los casos de Capital Federal y provincia de Buenos Aires para el periodo de entreguerras con pesquisas sobre enfermos de tuberculosis, o bien de aquellos que litigaron judicialmente a partir de la constitución del contagio venéreo como delito desde $1936 .{ }^{9}$ La participación de vecinos durante las epidemias de cólera y fiebre amarilla en Buenos Aires fue pesquisada por Maximiliano Fiquepron, ${ }^{10}$ mientras que Valeria Pita rastreó una variante de este tópico para el siglo XIX en clave de género al analizar las interacciones y significados de trabajadoras frente a la voz autorizada de los galenos. ${ }^{11}$

En esta dirección, este trabajo analizará expedientes en los que aparecen consignadas peticiones que vecinos de distintas localidades de la provincia de Santa Fe elevaron a los poderes públicos por cuestiones referidas a su salud durante la segunda mitad del siglo XIX. Nos interesa relevar la voz del pueblo y su ciudadanización, así como las tensiones que este informaba sobre el curso específico de la modernización y la medicalización en la provincia. Esta última, objeto de reflexiones sociológicas y filosóficas en los últimos cincuenta años, refiere a la expansión del saber médico desde el siglo XVIII sobre distintas esferas de la vida que no responderían a su competencia directa, estableciéndose como grilla de inteligibilidad social. ${ }^{12}$

Por otro lado, no pocas pesquisas historiográficas dialogaron con la antropología para pensar el lugar de los actores comunes y corrientes en la conformación de la cultura europea, así como el "descubrimiento" del pueblo por los sectores

8. Flurin Condrau, "The Patient's View Meets the Clinical Gaze”, Social History of Medicine 20.3 (2007): 525-540. DOI: 10.1093/shm/hkm076.

9. Diego Armus, "Historias de enfermos tuberculosos que protestan. Argentina, 1920-1940", Avatares de la medicalización en América Latina, 1870-1970, comp. Diego Armus (Buenos Aires: Lugar Editorial, 2005) 65-99; Carolina Biernat, "Jueces, médicos y enfermos: prácticas y sentidos en la construcción social del delito de contagio venéreo en Argentina durante la primera mitad del siglo XX”, História 38 (2019): 3. DOI: 10.1590/1980-4369e2019050.

10. Maximiliano Ricardo Fiquepron, "Los vecinos de Buenos Aires ante las epidemias de cólera y fiebre amarilla (1856-1886)”, Quinto Sol 21.3 (2017): 1-22. DOI: 10.19137/qs.v21i3.1230.

11. Valeria Silvina Pita, "De negociaciones cotidianas y de posibilidades históricas: una aproximación a los intercambios entre médicos y trabajadoras. Buenos Aires, 1870-1940", Anuario de Historia Regional y de las Fronteras 19.2 (2014): 365-390.

12. Aunque el concepto se atribuyó mayormente a la obra del Michel Foucault, su debate recupera las producciones de George Canguilhem, Iván Illich e incluso los distintos promotores de la antipsiquiatría de los años sesenta. Michel Foucault, El nacimiento de la clínica. Una arqueología de la mirada médica (Buenos Aires: Siglo XXI Editores, 2011). Los usos de este concepto en la pesquisa historiográfica local fueron revisitados en María Silvia Di Liscia y Ernesto Bohoslavsky, eds., Instituciones y formas de control social en América Latina, 1840-1940. Una revisión (Buenos Aires: Prometeo Libros / Universidad Nacional de General Sarmiento / Universidad Nacional de la Pampa, 2005). 
ilustrados en la conformación de los relatos nacionales durante el siglo XIX. ${ }^{13}$ La instalación de los sectores populares como objeto de estudio en Argentina, por su parte, ganó lugar luego del retorno democrático, lo que abrió una provechosa cantera de investigaciones en la historia política y urbana. ${ }^{14}$

El proceso de construcción estatal en espacios otrora coloniales resulta igualmente central. Por un lado, por su complejidad ante la conflictividad que abrió la disolución imperial ibérica. Por otro, para captar la emergencia de un tipo de autoridad entendida como moderna en sociedades que lejos estaban de serlo, y donde sus habitantes tuvieron una activa participación. ${ }^{15}$

En un contexto en el que los eventos epidémicos se multiplicaban al calor de las transformaciones económicas, con escasas certezas biomédicas para comprenderlos y tratar sus consecuencias, el cuidado de la salud era una preocupación que atravesaba a los habitantes de la provincia, por encima de su carácter lego y su pertenencia estatal o a la corporación médico-académica. A partir de esta premisa, estudiaremos los pedidos que sus habitantes elevaron a las autoridades con el objeto de entrever la construcción de una forma de ciudadanía en sus mutaciones. No obstante, esto implica problematizar qué tipo de fuentes pueden dar cuenta de la voz de los vecinos devenidos en ciudadanos durante el transcurso del siglo XIX.

Los estudios subalternos han cuestionado esta posibilidad de que actores como los vecinos devenidos en ciudadanos puedan "hablar" en las fuentes. ${ }^{16}$ Por encima de su carácter fragmentario, la hermenéutica que emprendimos parte de un presupuesto en el que, a menor sistematización estatal, más transparente resulta la expresión de la voz de las y los vecinos. Por el contrario, la configuración de instancias administrativas de gobierno impuso una serie de procedimientos que terminan por mediatizar dichas expresiones. Pero ello registra también dos procesos. Por un lado, las estrategias de los vecinos para valerse de tales mecanismos administrativos a su favor. Por otro lado, la interiorización de esas formas como parte de su ciudadanización. La restitución de estas escenas y la espacialización de los sectores

13. Robert Darnton, La gran matanza de gatos y otros episodios en la historia de la cultura francesa (México: Fondo de Cultura Económica, 2002); Peter Burke, Cultura popular en la Europa moderna (Madrid: Alianza Editorial, 2014).

14. Para la historia política véase Gabriel Di Meglio, Historia de las clases populares en la Argentina. Desde 1516 hasta 1880 (Buenos Aires: Sudamericana, 2012); Raúl O. Fradkin y Gabriel Di Meglio, comps., Hacer política. La participación popular en el siglo XIX rioplatense (Buenos Aires: Prometeo Libros, 2013). Para la historia urbana véase el trabajo de Diego P. Roldán, "La formación de los sectores populares urbanos en la historiografia argentina. Una mirada sobre el núcleo”, Signos Históricos 10.20 (2008): 194-232.

15. Germán Soprano, "El Estado en los extremos. Contribuciones de la historiografía hispanocolonial y la antropología de la política al estudio del Estado en el siglo XX", Estudios Sociales del Estado 1.1 (2015): 5-25. DOI: 10.35305/ese.v1i1.18; Ernesto Bohoslavsky y Milton Godoy Orellana, eds., Construcción estatal, orden oligárquico y respuestas sociales (Argentina y Chile, 18401930) (Buenos Aires: Prometeo Libros / Universidad Nacional de General Sarmiento, 2010).

16. Gayatri Chakravorty Spivak, ¿Puede hablar el subalterno? (Buenos Aires: El Cuenco de Plata, 2011). 
populares en el territorio provincial nos permite tensionar la profesionalización médica desde una arista poco explorada.

El corpus de fuentes se constituye de expedientes administrativos ingresados por vecinos en ejercicio del derecho de petición ante las autoridades, cuya relevancia en el ámbito hispanoamericano fue abordada por diversas pesquisas. En nuestro caso, nos interesa su reconfiguración en clave liberal durante la segunda mitad del siglo XIX, en especial luego de la Constitución de $1853 .{ }^{17}$ Recurrir a estas fuentes, además, diferencia este trabajo respecto a pesquisas que analizaron objetos similares pero desde expedientes judiciales que suelen incluir mayor espacio para el testimonio de los actores involucrados.

Estructuramos el artículo en cinco apartados. En un primer momento, especificaremos las características espaciales de la provincia de Santa Fe y sus principales transformaciones durante la segunda mitad del siglo XIX. Enseguida, continuaremos con el estudio de los casos, que será desarrollado en cuatro secciones. En cada una de ellas puntualizaremos las mutaciones en las formas de reclamar por su salud ante coyunturas específicas y las transformaciones institucionales del Estado.

\section{Una provincia de la Argentina: Santa Fe en el siglo XIX}

Los procesos revolucionarios que dieron lugar a la independencia en el Río de La Plata en 1810 fueron sucedidos por décadas de luchas intestinas entre distintos liderazgos militares regionales por la disputa del gobierno y la definición territorial de cada provincia; a lo que se le agregaban los conflictos de las provincias con Buenos Aires, ciudad puerto y concentradora de recursos fiscales aduaneros. Luego de la batalla de Caseros, ${ }^{18}$ la incorporación de Argentina en el esquema geopolítico del capitalismo y la llegada de masivos contingentes inmigratorios, la segunda mitad del siglo inauguró una etapa de mayor estabilidad en la que los conflictos comenzaron progresivamente a "civilizarse" en clave de lucha partidaria. ${ }^{19}$ En la provincia de Santa Fe, en particular, el proceso de construcción estatal que se inauguraba, anclado en una nueva fiscalidad sostenida por sus habitantes, generó nuevas formas de identificación y participación en lo público que oscilaron en el transcurso del siglo desde la condición de vecino ostentada por un gran número de inmigrantes hacia la de ciudadano. Junto con ello, los avatares de las estrategias colonizadoras ${ }^{20}$ sentaron las bases para la reorientación productiva de la provincia

17. Marta Bonaudo, "Hecho jurídico... hecho político. La conflictiva relación entre poder y justicia en la construcción de la República posible. Santa Fe, 1856-1890”, Política, cultura y religión. Del antiguo régimen a la formación de los estados nacionales. Homenaje a Reyna Pastor, coords. María Inés Carzolio y Darío G. Barriera (Rosario: Prohistoria Ediciones, 2005) 235-236.

18. La batalla de Caseros conllevó la derrota del gobernador de la provincia de Buenos Aires, Juan Manuel de Rosas, por parte del Ejército Grande al mando de Justo José de Urquiza, lo que dio lugar a la primera carta magna del país en 1853.

19. Marta Bonaudo, dir., Nueva historia argentina, t. 4 (Buenos Aires: Editorial Sudamericana, 1999).

20. El proceso de colonización argentina fue una estrategia concebida en distintos niveles estatales 
hacia un orden capitalista de producción en el cual una de las precondiciones fue la generación de un mercado de trabajo rural y la progresiva construcción de sentido en torno a la propiedad privada y su derecho. ${ }^{21}$

Sin embargo, el cúmulo de transformaciones económicas, sociales y políticas que atravesaron el territorio estuvo signado por el pulso específico que adoptó la modernización local al calor de sus límites materiales y sociales. Estos derivaron, a su vez, en una ingente cuestión social vivida y percibida tanto por las autoridades como por los habitantes,${ }^{22}$ tal como expusieron las distintas epidemias que azotaron los principales centros urbanos. ${ }^{23}$ En este registro, diversos saberes académicos ofrecían posibles estrategias para enfrentar las consecuencias no buscadas del progreso, y entre ellos se encontraba la medicina diplomada o académica. ${ }^{24}$

Las características geoclimáticas de la provincia de Santa Fe, atravesada por cinco sistemas hidrográficos — entre ellos el Río Paraná, segundo canal de navegación del país - fueron claves en el rol que esta desempeñó en la incorporación argentina al capitalismo y su capacidad de generación de riqueza. Sin embargo, esto no resultó homogéneo para el conjunto de su territorio, donde pueden diferenciarse tres regiones de ocupación y explotación del suelo: el productivo sur pampeano, con una fuerte impronta de grandes propietarios absentistas; la franja central, con la expansión del modelo de colonias agrícolas que generó pequeños y medianos propietarios agrícolas o ganaderos, y el norte chaqueño, escasamente poblado, de suelos pobres en fertilidad, pero densos en recursos boscosos que favorecieron la instalación de la compañía inglesa de extracción de tanino, la cual funcionó con grandes niveles de autonomía y arrasó con el ecosistema. ${ }^{25}$

Claro está que las variadas prácticas de salud a lo largo y ancho del territorio argentino antecedieron a las formas de organización político-administrativa cons-

en paralelo a los desplazamientos poblacionales del campo a la ciudad en diversas regiones europeas durante la segunda mitad del siglo XIX. Con el objetivo inicial de poblar el territorio e impulsar la actividad productiva, surgieron grandes diferencias entre provincias argentinas - $\mathrm{e}$ incluso al interior de cada una- dadas las variaciones regionales y el ritmo del proceso. Un abordaje del fenómeno en la región estudiada en Julio C. Djenderedjian, "La colonización agrícola en Argentina, 1850-1900: problemas y desafios de un complejo proceso de cambio productivo en Santa Fe y Entre Ríos”, América Latina en la Historia Económica 30 (2008): 129-157.

21. Marta Bonaudo y Elida Sonzogni, "Las resistencias y demandas ciudadanas frente a las lógicas del mercado y las políticas del Estado (Santa Fe, Argentina, 1890-1912)", América Latina en la Historia Económica 34 (2010): 237-267.

22. Juan Suriano, comp., La cuestión social en Argentina, 1870-1943 (Buenos Aires: Editorial La Colmena, 2000).

23. Diego Armus, "El descubrimiento de la enfermedad como problema social", Nueva historia argentina, t. 5, dir. Mirta Zaida Lobato (Buenos Aires: Editorial Sudamericana, 2000) 507-552.

24. A lo largo del trabajo diferenciaremos entre medicina diplomada o académica respecto a los otros actores y saberes del arte de curar, para distinguir así a los legitimados por el Estado de quienes realizaban su práctica en los márgenes de la legislación.

25. Ezequiel Gallo, La pampa gringa. La colonización agrícola en Santa Fe (1870-1895) (Buenos Aires: Edhasa, 2004). 
truidas luego de 1810, y por esta razón el fortalecimiento de algunas estructuras provinciales hacia mediados del siglo también se superpuso con aquellas. La institución que desde 1780 regulaba las cuestiones médicas era el protomedicato, una invención del Reino de España trasladada a sus dominios de ultramar durante el siglo XVII. Si los conflictos armados posteriores a 1810 desorganizaron dicho organismo - al tiempo que absorbieron sus funciones a la provisión de cuidados para las milicias - el periodo pos-Caseros permitió refundarlo en $1858 .{ }^{26}$ Con las limitaciones que imponía el frágil tendido de una autoridad pública en ciernes, este tipo de organismo fue la única voz del Estado en materia de salud, además de que era el encargado de regular los requisitos para quienes pretendiesen dedicarse a tal oficio, sucedidos por los consejos de higiene.

\section{Recurrir a la autoridad. ¿Gobernador o pater familias?}

A inicios de septiembre de 1847 Mercedes Jaimes, vecina de San Nicolás, se dirigía al gobernador de la provincia para implorar algún auxilio frente al estado mental de su marido Ramón Sorayre, quien se había desempeñado como sargento mayor y comandante en las tropas del caudillo. Desde hacía seis años Sorayre se hallaba "en la sencible privación del uso completo de sus potencias intelectuales por grave enfermedad que adolece, y en la incapacidad consiguiente de practicar por sí mismo diligencia alguna que requiera una personalidad legal". ${ }^{27}$ Desde ese momento, Mercedes asumió sus cuidados, aunque, tal como afirmaba, sus conocimientos médicos eran escasos y tenía a su cargo una numerosa familia con niños pequeños, quienes se veían "hoy oprimidos de una escasez considerable, sin bienes de que valernos, y tocando en la deficiencia de la precisa sustentación”. ${ }^{28}$ No obstante, Ramón percibía un tercio de los haberes del cargo en que se había desempeñado, dicha asignación resultaba insuficiente para cubrir las necesidades de este grupo familiar cercenado por las guerras posindependencia. Frente a semejante apremio, Mercedes recurría a la voluntad del brigadier solicitando otro socorro, sea por los sueldos denegados en su servicio militar — que aumentaban su pensión de veinte pesos-, o bien "de cualquier otro modo que VE juzgare conveniente y menos gravoso al Estado". 29

Meses más tarde, Santiago Quesada, vecino de San José del Rincón —próximo a la capital provincial—, escribía al gobernador solicitando la continuidad de un tratamiento iniciado por lepra tiempo atrás, por el cual había sido aislado de su familia durante un año en el paraje destinado a tal fin en su localidad. Ante "la grande mejoria que sentia, con la curación que abia enpesado en mi el medico, Don Juan

26. Federico Guillermo Cervera, Historia de la medicina en Santa Fe (Santa Fe: Colmegna, 1973).

27. 1847. AGPSF, Santa Fe, Gobierno, t. 10, exp. 4, f. 124.

28. 1847. AGPSF, Santa Fe, Gobierno, t. 10, exp. 4, f. 124.

29. 1847. AGPSF, Santa Fe, Gobierno, t. 10, exp. 4, f. 124. 
Jose Muños, abiendo sido esta suspendida por Orden Superior", ${ }^{30}$ Quesada pedía al gobernador que ordenara su examinación por un facultativo "y si estoy radicalmente curado, para poder con franquesa recojerme a sino de mi familia, siendo de mi cuenta los gastos que se originasen de otro mi reconocimiento". ${ }^{31}$ Ante su pedido, dos médicos presentaron su opinión. El primero planteaba que había reconocido su enfermedad y lo veía "bastante curado" luego de un año. El segundo, empero, señalaba que no podía encontrar en el susodicho vecino indicio alguno de haber padecido lepra,

por consiguiente no ha sido mas que una cosa la dolencia de este hombre, como ya lo había manifestado en su reconocimiento anterior hecho en el [...] lo mismo que de algunos otros reputados también afectados [...] Por no permitirlo la estreches del papel no da el que firma mas detalles y explicaciones pero esta pronto a darlas tal como se le exigen y a rebatir también al que se le presente al Sr Quesada de haber sido Lazarino. Esta completamente curado de su dolencia sencilla que bien existido solamente en los lobulos de las orejas. ${ }^{32}$

A continuación, el gobernador decretó que un tribunal de facultativos estudiase el avance de su enfermedad y se expidiese al respecto, aunque sin respuesta definitiva sobre el asunto. Este tipo de decisiones no eran infrecuentes, pues veremos que un año más tarde Leandro Esquivel apelaba a la clemencia del jefe militar y político en nombre de su madre, quien había sido recluida en tal paraje por su enfermedad. ${ }^{33}$ Estos tres peticionantes exponen dos experiencias concretas sobre las prácticas de cura y las incertidumbres en el contexto decimonónico argentino: las consecuencias personales de los conflictos armados posindependencia y el abordaje de la lepra. Si en ambas la apelación a la autoridad política evidencia su percepción cercana y personalizada en un caudillo militar, también muestra el registro específico que tenían de esta última y sus implicancias sobre la salud de la población local. Si el gobernador recurría a la voz facultada de los diplomados, las y los vecinos recurrían, en cambio, al gobernador como interventor - como autoridad protectora - frente a los procedimientos de instituciones sanitarias como los lazaretos.

Distinto fue el pedido que 18 habitantes de San Gerónimo de Coronda realizaron a fines de 1864 en el cual apelaban al gobernador por ayuda médica frente al impacto de algunas enfermedades, que entendían como epidémicas por su recurrencia en el tiempo y desarrollo extraordinario: "sin que se haya notado disminución alguna, sin embargo del cambio de estación y de haber llovido algunas veces, motivos suficientes que podrían haber contribuido a su total desaparición pues, que sin embargo de la templanza de la atmosfera parece que hoy se presenta

30. 1847. AGPSF, Santa Fe, Gobierno, t. 10, exp. 4, f. 431.

31. 1847. AGPSF, Santa Fe, Gobierno, t. 10, exp. 4, f. 431.

32. 1847. AGPSF, Santa Fe, Gobierno, t. 10, exp. 4, f. 431.

33. 1847. AGPSF, Santa Fe, Gobierno, t. 10, exp. 4, f. 666. 
de un modo recrudeciente manifestándose sucesivamente bajo nuevos síntomas que tienen alarmada a la población". ${ }^{34}$

Lo curioso radica en el desconcierto que este colectivo manifestaba por la invariabilidad del fenómeno, a pesar de los cambios climáticos de la región. De esta manera, vemos la circulación y apropiación de concepciones medioambientalistas en el desarrollo de las enfermedades, propias de la literatura médica de la época. ${ }^{35}$ En este sentido, los vecinos requerían auxilio médico frente al flagelo que los afectaba, dado que la escasa población local había desestimado la instalación de diplomados en el pasado. Por ello, pedían al gobernador la asignación de un facultativo "ya sean de los que esisten en la Capital o de los del Rosario [...] al fin de que asociado al ciudadano Dn Felipe Fernandez el único con que actualmente cuenta la poblacion como Medico, puedan en cuanto les sea posible contener el desarrollo de dichos males, o buscar algún jenero de preservacion". ${ }^{36}$

Si la persistencia del fenómeno epidémico - y la incertidumbre para comprenderlo - marcaban la experiencia de este poblado y su consecuente apelación a los poderes públicos, al mismo tiempo esto expone la presencia de otros actores no diplomados en la escena. Por su contraste con lo que veremos en años posteriores, lo interesante aquí es que no se requirió autorización para su desempeño, sino que se pedían refuerzos, pues la población local confiaba en su práctica. Pasados unos días, el ministro comisionó al médico de policía de la capital al departamento de San Gerónimo para atender a la población y contener el evento epidémico.

La continuidad de estos fenómenos adelantaba la primer gran epidemia de cólera que azotó los grandes centros urbanos, acaecida apenas dos años luego. Junto con la fiebre amarilla — sucedida décadas después-, el cólera fue la primera enfermedad que durante la segunda mitad del siglo puso seriamente en jaque a la población y las autoridades, y no solamente por sus características biológicas y su alta mortalidad. Al tiempo que diversas teorías médicas disputaban formas de comprenderla y actuar en consecuencia, la infraestructura sanitaria de las grandes urbes exponía su insuficiencia y las precarias condiciones de vida favorecían su propagación. Si todos esos factores detonaban una miríada de sentidos sobre cómo interpretar la crisis, una cuestión fundamental era que la confianza de la población residía más en sanadores y comerciantes que en los mismos facultativos. ${ }^{37}$

Ante semejante crisis, va de suyo que el impacto provincial no se haría esperar. En agosto de 1867, un número no menor de 181 vecinas y vecinos de San José y Calchines escribieron al gobernador debido al crecimiento poblacional y la ausencia

34. 1864. AGPSF, Santa Fe, Gobierno, t. 25, exp. 85, f. 857.

35. Flavio C. Edler, "De olho no Brasil: a geografia médica e a viagem de Alphonse Rendu", História, Ciências, Saúde - Manguinhos 8 (2001): 925-943.

36. 1864. AGPSF, Santa Fe, Gobierno, t. 25, exp. 85, f. 857.

37. Maximiliano Ricardo Fiquepron, "Lugares, actitudes y momentos durante la peste: representaciones sobre la fiebre amarilla y el cólera en la ciudad de Buenos Aires, 1867-1871", História, Ciências, Saúde-Manguinhos 25.2 (2018): 335-351. DOI: 10.1590/s0104-59702018000200003. 
de médico diplomado allí o en los alrededores. Pedían entonces que autorice a Visente Bital, sanador que contaba con la estima local:

que caresiendo en los referidos Departamentos, de un médico, para atender a los enfermos, pues lo exije ya el cresido número de habitantes, que no novajaron de dos mil quinientos á tres mil, venimos ante V.E. a pedir al Sr. Dn. Visente Bital por ser ya consido de todos, y haber echo acá varias curas notables, o que nos prueba, los buenos conosimientos prácticos que tiene, y á mas de esto, lo umanitario y desinteresado que se á manifestado, por todo lo espuesto esperamos queV.E. accederá a nuestra solicitud, por la escasez que tenemos de médico, y por que en este tenemos confianza. ${ }^{38}$

Como puede observarse en el remate de esta presentación, la confianza de la población era central como argumento para la autorización. Sin desconocer el lugar de la medicina diplomada y sus practicantes, las y los vecinos apelaban al vínculo construido entre un sanador y los residentes a través del cual, además, Bital había demostrado su capacidad "práctica". Por otro lado, el número de vecinos movilizados permite inferir varios factores: en primer lugar, el carácter colectivo de la experiencia en los eventos de salud y enfermedad. En segundo lugar, el posible alcance que la epidemia de cólera en curso podía estar adquiriendo en la localidad. Por último, informan los intentos de mayor control por parte del protomedicato, así como la eventual presencia cercana de algún diplomado que objetase su desempeño.

\section{La creación del Consejo de Higiene y nuevos formatos de petición}

El impacto que la epidemia de cólera tuvo en la provincia impulsó la creación de una nueva institución que velase por la salud de sus habitantes: el Consejo de Higiene. Con sus dos sedes en la capital y la ciudad de Rosario, el abanico de sus atribuciones estatutarias evidencia una mayor voluntad de registro estatal sobre una variedad de cuestiones sanitarias. Así, el organismo se proponía controlar las prácticas privadas, habilitar títulos extranjeros o de otros consejos provinciales, autorizar los llamados "ramos menores" — parteras, flebótomos_-, las farmacias y la inspección de establecimientos ante nuevos brotes epidémicos. Sin embargo, su principal propósito residía en el resguardo del ejercicio profesional de los diplomados respecto a otros actores del arte de curar. ${ }^{39}$ Ante la notable presencia de curanderos y sanadores, pero también de numerosos diplomados extranjeros - explorada en pesquisas previas-, podemos afirmar que durante sus primeras décadas de funcionamiento el organismo se ocupó de la salubridad local a través de sus ensayos por configurar un mercado regulado para el ejercicio médico. ${ }^{40}$

38. 1867. AGPSF, Santa Fe, Gobierno, t. 31, exp. 22, n. 88, f. 1074.

39. Provincia de Santa Fe, Registro Oficial (1867-1869) (Santa Fe: Imprenta Oficial, s.f.) 240-245.

40. Hemos explorado los intentos de construcción de ese mercado regulado de profesionales en José Ignacio Allevi y Adrián Carbonetti, "Peticiones y prerrogativas. Médicos y boticarios en la corporativización del arte de curar y la conformación del Estado provincial en Santa Fe, Argentina (1857-1903)", Varia Historia 35.69 (2019): 753-786. DOI: 10.1590/0104-87752019000300004. 
En ocasiones, las tentativas de control del Consejo sobre ciertas prácticas resultaban estrictas. Así ocurrió durante 1875, cuando prohibió a Francisca Casas su ejercicio como partera en la ciudad de Rosario. En reacción a este hecho, 113 damas de la urbe portuaria apelaron al gobernador para procurar se autorice a quien durante 28 años las había acompañado "en épocas anteriores en que la personas que habían hecho estudios científicos de esta materia eran desconocidos en el país". ${ }^{41}$ La importancia de su servicio no provenía solo de los lazos que estrechaba con las parturientas, sino que, además, asistía gratuitamente a las mujeres que no podían cubrir sus servicios

Mashaora, cosa incrible! Se le proive a esta pobre muger que ejersa los oficios de caridad y amistad, dejando de este modo a la clase proletaria y menesterosa de esta sociedad, en casos tan graves por su naturaleza, sin los aucilios de esta desinteresada y abnegada hija del pueblo, que no exige a la clase proletaria remuneración ninguna, y se contenta solo con lo que graciosamente se le quiera dar. Inspiradas en los nobles sentimientos de gratitud que son inerentes al noble corazón de la muger argentina, pedimos a V.E. se digne permitir a Francisca Casas el libre ejercicio en los oficios de partera cuando sea llamada por las madres de nuestra sociedad. ${ }^{42}$

Atentas a que las objeciones del Consejo apuntarían a su falta de certificación académica, las peticionantes utilizaron una estrategia doble. Por un lado, esgrimieron su propia experiencia con Francisca, para lo que adjuntaron testimonios y firmas. ${ }^{43}$ Pero, además, convocaron a dos médicos para que refrendasen la pericia de su matrona. El primero señalaba que Francisca lo había convocado siempre a tiempo y que nunca se había osado administrar ningún tipo de remedio para las inflamaciones propias del parto. El segundo diplomado, por su parte, esgrimía

que habiéndome pedido varias señoras a las que yo he asistido durante el puerperio que diga si he notado alguna manipulación imprudente practicada por la partera Francisca Casas: declaro en conciencia que en tres de dichas señoras a quien tuve ocasión de asistir jamas note y ni encontré en dichas parturientas ninguna alteración que me haya hecho sospechar ninguna manipulación; al contrario se me llamo muy oportunamente y en una tube que operar; cuya operación podía ella practicarla si lo creiera oportuno. ${ }^{44}$

En respuesta al reclamo, el ministro de gobierno reivindicó la potestad reglamentaria del Consejo para limitar ejercicios profesionales no diplomados con lo cual sugería al gobernador que acompañe la moción inicial de no autorizar a Francisca. ${ }^{45} \mathrm{Al}$ informarlas sobre la resolución negativa de su caso, el ministro

\footnotetext{
41. 1875. AGPSF, Santa Fe, Gobierno, t. 42, f. 1302.

42. 1875. AGPSF, Santa Fe, Gobierno, t. 42, f. 1302.

43. 1875. AGPSF, Santa Fe, Gobierno, t. 42, ff. 1306-1308.

44. 1875. AGPSF, Santa Fe, Gobierno, t. 42, f. 1304.

45. 1875. AGPSF, Santa Fe, Gobierno, t. 42, f. 1309.
} 
sugirió al colectivo femenino que elevase su reclamo a las cámaras legislativas de la provincia para modificar el texto de la ley, dado que su pedido conllevaba suspender disposiciones legales establecidas, y dicha atribución no correspondía al Poder Ejecutivo.

Algunos años más tarde, en noviembre de 1884, 20 vecinos de San José Del Rincón recurrieron al ministro de gobierno solicitando el nombramiento de un médico para el poblado. No obstante, dada la escasez de habitantes y su experiencia previa afirmaban que el diplomado asignado no podría solventarse solo con sus consultas. Su pedido, entonces, era que el Estado aportase a su sostenimiento "en atención a la grave necesidad que en esta población se siente de un médico que pueda proporcionar los necesarios recursos a los enfermos y siendo ella sobremanera escasa de recursos, venimos respetuosamente [...] a fin de que en vista de tan sentida necesidad, se sirva ayudar con una suvencion para el establecimiento de un medico en este punto, el que consta de una población de 2300 habitantes". ${ }^{46}$

Ahora bien, como ya observamos, en ocasiones los peticionantes ya contaban con un candidato en quien confiaban cuando formalizaban su solicitud. En este caso, pretendían que Ricardo de Gatell, un boticario reciente en la localidad, cumpliese tales funciones dado que "esta dando pruebas de suficiente competencia en la materia, y se hacia de todo punto imposible su subsistencia sin la suvencion indicada". ${ }^{47}$ Luego de un mes y medio, el ministro informó que no haría lugar a la solicitud, pues no existían partidas presupuestarias a tal efecto. ${ }^{48}$

Las peticiones de este periodo exponen claramente las prioridades del Consejo como organismo estatal: resguardo del celo profesional y establecimiento de criterios para los ramos menores. Sin embargo, en dicho afán se interponían sus limitaciones como agencia estatal: en la contradicción de proteger la actividad médica diplomada sin contemplar el establecimiento rentado de los mismos y en el que los estímulos locales no eran suficientes. Si observamos a los solicitantes, empero, el caso de Francisca Casas expone cómo las vecinas de la ciudad económicamente más dinámica de la provincia — Rosario - lograron aplicar estrategias que combinaban elementos administrativos y legales para alcanzar su cometido.

\section{Un nuevo Consejo, nuevos recursos vecinales}

El pulso acelerado del crecimiento económico y poblacional estimulado por las sucesivas oleadas migratorias derivó rápidamente en otra escena de crisis que expuso los confines de un Estado apenas delimitado como tal. Durante 1886 la epidemia de cólera que azotó el territorio señaló la escasez tanto de médicos autorizados como de agencias que pudieran ocuparse. Al igual que en 1867, la respuesta estatal y corporativa frente a los efectos colaterales de la modernización derivaron

46. 1875. AGPSF, Santa Fe, Gobierno, t. 79, exp. 27, n. 38, f. 442.

47. 1885. AGPSF, Santa Fe, Gobierno, t. 79, exp. 27, n. 38, f. 442.

48. 1885. AGPSF, Santa Fe, Gobierno, t. 79, exp. 27, n. 38, f. 443. 
en la reforma institucional del Consejo de Higiene. Con ello, centralizó su peso político en la capital provincial — subordinaba a esta la sede de Rosario-, reforzó su potestad en la autorización de títulos extranjeros, el avalúo de honorarios, la aplicación de penas por ejercicios irregulares y la inspección edilicia e higiénica en farmacias, con lo que adoptó, además, la farmacopea francesa. El Poder Ejecutivo, en tanto, nombraría a los miembros del tribunal y sus inspectores - otrora elegidos por votación y no sin conflictos entre las sedes-, que pasarían a ser funcionarios estatales remunerados. $^{49}$

El mismo año en que la segunda epidemia de cólera conmocionaba la provincia se suscitó un conflicto muy particular en su capital. Desde hacía algunos años, el espiritista Juan Pablo Quinteros prestaba sus servicios curativos como parte de su misión religiosa, mas luego del pasaje de la epidemia fue acusado por ejercicio ilegal de la medicina por el Consejo de Higiene. Como hemos analizado en otros trabajos, ante dicha imputación, Quinteros recurrió a un asesor letrado y presentó una demanda en contra del presidente del Consejo, el real promotor de su causa. En ella se expusieron una miríada de cuestiones que informaban sobre la posición de dicho personaje en la sociedad santafesina, como así también sobre el estado del arte de curar local en el fin de siècle. ${ }^{50}$ En la coyuntura abierta por su interposición legal, un petitorio de 112 vecinos se sumó a su defensa. Si bien resulta innegable la influencia de su representante legal en dicha presentación, la reunión de testimonios en favor del espiritista y el objeto de la misiva - requerir al Estado que rectifique su accionar - invitan a considerarla. Allí, vecinas y vecinos apelaban al gobernador desde su imposibilidad de adquirir los medicamentos que la ciencia médica requería en sus curaciones, lo cual volvía un contrasentido recurrir a su saber en busca de curas. Ello no implicaba desconocer su experticia, pues tal como afirmaban: "Nada decimos de los médicos porque ellos, con la mejor y mas buena voluntad, en cualquier momento que se los llame, acuden solicitos a nuestras llamadas. Mas no sucede asi con los medicamentos que sin dinero no podemos adquirirlos: hay que pagarlos al contado". 51

En ese sentido, el servicio que brindaba este espiritista suplía dicha necesidad, pues su forma de cura consistía en dispensar agua magnetizada. Dado el contenido religioso de su práctica, ${ }^{52}$ su predisposición y escucha del sufriente señalaban una franca diferencia con el proceder de la medicina diplomada, pues "donde quiera que se le llame, sean personas pudientes o pobres, muchas veces hemos obtenido

49. Provincia de Santa Fe, Registro Oficial (1887) (Santa Fe: Imprenta Oficial, s.f.) 159-167.

50. Paula Sedrán y otros, “Juan P. Quinteros, espiritista. Disputas por los sentidos legítimos del arte de curar. Santa Fe, fines del siglo XIX”, Revista de Indias 78.274 (2018): 819-843. DOI: 10.3989/ revindias.2018.025.

51. 1887. AGPSF, Santa Fe, Gobierno, t. 88, exp. 22.

52. Las prácticas de cura tanto diplomadas como religiosas presentaban sendas diferencias en su contenido como en sus objetivos. Véase una aproximación a los mismos desde la especificidad del espiritismo en Beatriz Teixeira Weber, "Espiritismo e Saúde: concepções a partir das práticas numa sociedade kardecista", Revista Brasileira de História das Religiões 5.15 (2013): 19-46. 
la salud mediante sus sencillos medicamentos, hasta ahora su reputación como medico o curandero no nos ha sido perjudicial: el publico conoce cuanto decimos y exponemos ante VE". ${ }^{3}$ Es por ello que este nutrido grupo solicitaba al gobernador que permitiese a Quinteros ejercer libremente su misión religiosa y sus curaciones, "de hacer bien al que lo necesite por medio de sus conocimientos". ${ }^{54}$ Pero también insistían en que se le devuelva el dinero que le habían cobrado como multa por ejercicio ilegal de la medicina. El petitorio se adjuntó al expediente del caso, aunque la resolución no fue consignada en el mismo. No obstante, incluso si la estrategia argumental y su contenido hubiesen correspondido al representante legal del espiritista, lo cierto es que dichos vecinos exponían situaciones concretas; por encima de la creencia en la medicina diplomada o el espiritismo, el proceso de cura involucraba productos farmacéuticos del primer caso. Con ello es posible atisbar que esto podría haber sido un factor más en la opción por los actores no diplomados, independientemente del avance del saber médico.

Dos años después, 25 vecinos de estación Gálvez recurrieron a las autoridades ante el crecimiento del poblado y las dificultades de sus habitantes para afrontar los gastos que la asistencia médica demandaba. Es por esto que solicitaban se destine un cargo de médico de policía con obligación de prestar gratuitamente sus servicios a los enfermos pobres, junto con lo que pudiese obtener de sus curas particulares. No obstante, la figura del médico de policía no contemplaba en sus funciones aquello que los vecinos anhelaban. Dicho cargo se vinculaba con tareas propias de la fuerza policial, al tiempo que resultaba una instancia de visibilidad para los diplomados, razón que los motivaba a disputar sus nombramientos. ${ }^{55}$ Como correlato de su petición, además, detallaban un conjunto de situaciones cotidianas del poblado que convocaban la necesidad de un galeno:

Esta necesidad es más sentida para los muchos niños de la población, lo que por su tierna edad son los que están expuestos a enfermarse, y por tener aquí un hotel de inmigrantes a donde continuamente familias pobres y con muchas creaturas. La necesidad de un médico que resida en el pueblo se hace mas evidente en los casos de enfermedad improvisa, como ser: heridas por pelea, por caídas, por desgracias en los movimientos de los trenes, por envenenamiento casual, etc. Estos casos reclaman la inmediata asistencia del médico, pues (como ya se dio caso), la demora para mandar a llamar a un medico de otro pueblo puede causar graves perjuicios y hasta la muerte del enfermo. ${ }^{56}$

Este caso expone una situación usual para los habitantes del territorio ante la desigual distribución de los escasos profesionales autorizados en la provincia. En efecto, en Estación Gálvez residía el médico Máximo Hirsch, pero "siéndole escaso

53. 1887. AGPSF, Santa Fe, Gobierno, t. 88, exp, 22.

54. 1887. AGPSF, Santa Fe, Gobierno, t. 88, exp, 22.

55. Hemos observado esta cuestión en Allevi y Carbonetti.

56. 1889. AGPSF, Santa Fe, Gobierno, t. 123, exp. 11. 
para su mantenimiento lo que le rinden sus curas a las familias que pueden pagar, ha determinado cambiar de residencia para irse a establecer en otro punto mas conveniente a sus intereses" ${ }^{57}$ Esta situación, que ya hemos visto en casos anteriores de este trabajo, expone, a su vez, el uso estratégico que los vecinos buscaban hacer de un cargo administrativo para suplir sus necesidades de atención médica para lo cual apelaban a su necesidad de que se amplíen excepcionalmente sus funciones. Empero, la respuesta oficial fue negativa por falta de fondos presupuestarios.

Un caso más complejo se presentó años más tarde cuando, en los últimos días de 1894, vecinos del pueblo de Sunchales - región particularmente productiva de la provincia - movilizaron a sus propias autoridades civiles en pos de un personaje particular. Frente al azote que el cólera infligía y el traslado del único médico autorizado a la provincia de Córdoba, intentaron que Manuel Martínez Olano - curandero perseguido y multado por el Consejo - pudiera brindar atención en tal coyuntura. En esta dirección, el comisario general de la localidad, Pedro Manchado, se dirigió al ministro de gobierno manifestando "que esta población está alarmada con la epidemia del cólera y la falta de médico por haberse ausentado el que había aquí [...] Digame si SS. le podrá permitir [que cure] en vista de las circunstancias por que atraviesa esta población". ${ }^{58}$ El telegrama adjuntaba otro, firmado por el juez de paz local. A la par que este rescataba la preocupación colectiva por la epidemia, agregaba que más allá de la prohibición del Consejo "vecinos respetables reclaman los servicios de Martínez Olano". ${ }^{59}$ Sumado a ello, un número de "industriales" de la zona, encabezados por Adolfo K. Gielz, adhirieron al pedido frente al avance del flagelo que los alarmaba y en carencia de médico oficial para que, de manera urgente, el ministro "ponga en conosimiento del Sr. gobernador que encuentrase aquí el Sr. Martinez Olano, medico extranjero que esta inhibido por el Consejo de Higiene a ejercer su profesión. Por las circunstancias espuestas pedimos [...] para que este Sr. pueda ejercer la medicina y poder a la vez tomar medidas preventivas contra la epidemia reinante" ${ }^{60}$

El expediente ingresó en la capital seis días después con recomendación de pronta resolución. El organismo revindicaba su potestad reglamentaria para facultar el ejercicio médico de quienes carecían de título universitario. Al mismo tiempo, recordaba que este personaje ya había sido multado en dos ocasiones por continuar en su práctica, cuya multa, además, estaba impaga. Los funcionarios esgrimían que habilitar a Martínez Olano implicaría "abandonar la suerte de aquellos habitantes en manos de un particular, lo que significa acarrearse la responsabilidad de los actos de aquel". ${ }^{61}$ Ante el posible avance del cólera, afirmaban que

57. 1889. AGPSF, Santa Fe, Gobierno, t. 123, exp. 11.

58. 1894. AGPSF, Santa Fe, Gobierno, t. 210, exp. 5.

59. 1894. AGPSF, Santa Fe, Gobierno, t. 210, exp. 5.

60. 1894. AGPSF, Santa Fe, Gobierno, t. 210, exp. 5.

61. 1894. AGPSF, Santa Fe, Gobierno, t. 210, exp. 5. 
enviarían un nuevo facultativo, si bien en el mismo escrito señalaban no tener con quien cubrir la vacante dejada por el doctor Carlos Achaval.

Junto al involucramiento de vecinos destacados de la zona por su condición propietaria - los “industriales” presididos por Adolfo K. Gielz-, la participación directa de funcionarios estatales como el comisario o el juez de paz nos permiten sumar dos reflexiones a la escena que buscamos restituir en este trabajo. Por un lado, que la recurrencia e impacto de ciertas enfermedades en términos de mortalidad y su permanencia superaba a los eventos epidémicos específicos que ganaban visibilidad en la esfera pública. Por el otro lado, que la preocupación por la atención médica aunaba a los miembros de una comunidad, lo cual se expresa en el involucramiento de actores estatales en el petitorio como el comisario o el juez de paz.

\section{Vecinos enfrentados}

Una situación más atípica se presentó con el cambio de siglo en la localidad de Villa Gobernador Gálvez, ubicada al sur de Rosario. Allí, en febrero de 1907 la Comisión de Fomento local se dirigió al ministro de gobierno requiriendo su intervención en un asunto por el que bregaban desde el mes anterior: el traslado de su médico local, Henry Hollemaert. Si bien contaba con autorización estatal, los miembros de la Comisión insistían que dicho acto se efectuó

\footnotetext{
sin tener en cuenta que el supuesto médico Dr. Hollemaert, no reúne tales condiciones ni posee documentos que puedan habilitarlo legalmente para el ejercicio delicado de la medicina y que por un puro favoritizmo perjudicial a los habitantes el Consejo de Rosario lo autorizó, resultando hoy que convencida la población de esta jurisdicción que el referido Sr. Hollemaert, a más de explotar sin comprensión, cobrando quince veinte y hasta treinta pesos $\mathrm{m} / \mathrm{nac}$ por cada certificado médico, no acierta ninguna cura y la mayor parte de los pacientes sucumben. ${ }^{62}$
}

En primer término, si bien no era habitual, la corporación galénica disponía de la potestad de autorizar a diplomados nacionales cuando estaban próximos a graduarse. ${ }^{63}$ Sumado a ello, la sede de Rosario presentaba no pocas discrepancias con la capitalina, en especial luego de la modificación del reglamento y la centralización de las decisiones en esta última. Sin embargo, el reclamo de la Comisión era más amplio: el "galeno" en cuestión no solo estaría escasamente formado, sino que su impericia obligaba a que los habitantes se movilizasen a Rosario para recibir atención. Por si fuera poco, si fallecía el paciente, "efectúan las inhumaciones en perjuicio de las rentas de esta comuna y de los vecinos que en mérito de lo referido, resulta que ninguno de los habitantes llama al medico mencionado". ${ }^{64}$

62. 1907. AGPSF, Santa Fe, Gobierno, Sección Agricultura, t. 442 bis, exp. 43.

63. Exploramos estas excepciones en Allevi y Carbonetti.

64. 1907. AGPSF, Santa Fe, Gobierno, Sección Agricultura, t. 442 bis, exp. 43. 
No obstante el enfático reclamo de la comuna, un grupo de vecinos y comerciantes tomó conocimiento de sus intenciones e interpuso su propia versión del asunto. Fue así como 62 firmantes se proclamaron a favor del desempeño del médico. Señalaban su capacidad técnica y su aprecio por este

en vista de la campaña tan injusta que se le promueve al medico de esta localidad Dr. Henry Hollemaert nos permitimos elevar a V.S. la presente en son de protesta a los cargos hechos al Señor Hollemaert; el cual desde cerca de siete años cumple su misión en estas con verdadero desinteres y se supo grangear una numerosa clientela. Esperamos deVS tomará en consideración la presente como prueba de adhesion y cariño de este vecindario en favor del Señor Hollomaert. ${ }^{65}$

Recibidas ambas peticiones, días más tarde el ministro recondujo el expediente al Consejo de Higiene rosarino, el cual expidió su parecer rápidamente. En su informe indicaba que el señor Hollemaert fue autorizado en 1901 para ejercer en la citada localidad, pues, además de los certificados de alumno de cursos superiores de medicina que presentó, vecinos del poblado habían solicitado su radicación. Por encima de estas consideraciones y de sus estudios incompletos, su validación respondía a que

ningún medico diplomado quería instalarse en ese punto dado lo insignificante de su población, que durante mas de sus años que han transcurrido, nunca se ha presentado una queja a este Consejo a cerca de la conducta del Sr. Hollemaert y por el contrario son muchas las personas que han manifestado su agradecimiento por su filantrópica y humana voluntad en el desempeño de su misión. ${ }^{66}$

Por si fuera poco, el Consejo avanzó sobre el accionar de la Comisión de Fomento, pues entendía "antojadizos e irrespetuosos los conceptos de la nota" al cuestionar las resoluciones emanadas de dicha agencia en la que no mencionaban ningún caso concreto de mala praxis. En resumen, desestimaba de plano la denuncia y sostenía su veredicto inicial, mientras juzgaban que la misiva "en contra de la conducta del Sr. Hollemaert obedece solamente a bajas pasiones y resentimientos personales de algún miembro de la misma". ${ }^{67}$ En vista del cruce de peticiones y la respuesta del Consejo, el fiscal interviniente expidió el 2 de marzo la recomendación al ministro de no dar lugar al reclamo de la Comisión de Fomento en pos de la voluntad popular y ausencia de quejas contra Hollemaert.

Sin embargo, la disputa lejos estaba de una solución definitiva. El mismo 2 de marzo otro grupo de 120 vecinos "propietarios, comerciantes, industriales de esta jursidicción" recurrieron al presidente de la Comisión para exponer su malestar con el desempeño de este sanador. Argüían su falta de conocimientos, así como la

65. 1907. AGPSF, Santa Fe, Gobierno, Sección Agricultura, t. 442 bis, exp. 43.

66. 1907. AGPSF, Santa Fe, Gobierno, Sección Agricultura, t. 442 bis, exp. 43

67. 1907. AGPSF, Santa Fe, Gobierno, Sección Agricultura, t. 442 bis, exp. 43. 
imposición que resultaba en quienes no confiaban en su criterio de movilizarse hasta la urbe portuaria para recibir atención médica:

Siendo de imperiosa necesidad un facultativo en esta extensa colonia que posee los dotes y títulos que comprueven los estudios para ejercer la delicada misión de la medicina, pues el que fue autorizado temporariamente hase cuatro años, Don Enrique Hollemaert, no responde al deceo de todo el vecindario por no saber el arte de curar y por no haber cursado los estudios para tan difícil profecion pues por falta de un facultativo idóneo, los enfermos de esta colonia pasan a curarse en el Rosario perjudicándose todo el vecindario por tener un medico incompetente y abusivo. ${ }^{68}$

Días después, la Comisión manifestó su apoyo formal a este último grupo, pues "considera justo como verídico el reclamo que hace el vecindario" . ${ }^{69}$ No obstante la abrumadora diferencia de firmantes en una y otra presentación, el criterio que primó para la resolución final del conflicto fue otro: a fines de abril, el ministro se abstuvo al veredicto inicial del Consejo, que había ratificado su autorización del cuestionado "casi" médico.

Este caso resume de forma clara el cruce de tensiones que atravesaba a las condiciones de acceso a la salud a inicios del siglo XX: un médico sin título en pleno ejercicio, una agencia estatal que lo legalizaba, tensiones internas al propio Estado, vecinos movilizados con posiciones encontradas. A diferencia de las peticiones anteriores que revisamos, su particularidad reside en que la corporación galénica sostuvo a Hollemaert incluso luego de seis años de su autorización condicional. De esta manera, el factor que indefectiblemente emerge como constante es la limitación de profesionales acreditados como único resguardo al cuidado de salud de la población.

\section{Consideraciones finales}

Los requerimientos populares aquí reunidos componen una escena particular sobre actores, representaciones y materialidades de la salud, la enfermedad y el arte de curar en una provincia argentina durante la segunda mitad del siglo XIX. Con la inserción del país en un nuevo esquema mundial y el arribo de miles de inmigrantes, el territorio de Santa Fe se transformó al calor de una nueva y dinámica sociedad. Por encima de su carácter fragmentario, los casos aquí elegidos contienen una potencialidad cualitativa que visualiza mutaciones sustanciales en la construcción tanto de la ciudadanía como en la del arte de curar en esta modernidad provinciana.

En primer término, nos permiten observar la vitalidad y evolución del ejercicio del derecho de peticionar a la par de la progresiva conformación de una autoridad estatal moderna y despersonalizada, como muestran los cambios en la estructura 
de las solicitudes, su lenguaje y el sujeto de su apelación. Esta delimitación de un Estado provincial, sin embargo, no se tradujo en la práctica en una mayor capacidad de control o aplicación de la legislación atinente a la salud. Si los funcionarios encargados de cumplir tales disposiciones eran al mismo tiempo vecinos, su reticencia también muestra el nivel de legitimidad que las prácticas no diplomadas tenían.

En segundo término, por su cobertura temporal y espacial estos casos exponen la evolución de la figura estatal, las trasformaciones institucionales acaecidas y, sobre todo, las modificaciones en las formas y contenido de las peticiones hacia su “ciudadanización”. En este sentido, y en línea con pesquisas que lo abordaron específicamente, la construcción del individuo liberal en Argentina fue interiorizada como instancia colectiva. Es así como se pasa de presentaciones individuales en 1847-1848 hacia la reunión de firmas luego de 1852. No obstante, al compás de las tensiones emergidas con las transformaciones socioeconómicas de la provincia, esta condición colectiva presente en la casi totalidad de los documentos expone el grado de movilización que conllevaba la enfermedad. En las ocasiones analizadas, vecinas y vecinos acordaron que la protección de su salud era de interés común. Pero también formulaban sus pedidos en un lenguaje y unos contenidos acordes a su interlocutor estatal.

Por otra parte, estos casos exponen que la experiencia de la enfermedad atravesaba de manera colectiva: desde los familiares abocados al cuidado hasta a la reunión de adhesiones en defensa de un sanador, y que la atención de los padecimientos se desarrollaba en ámbitos domésticos. Al tiempo que iluminan la cotidianeidad de la enfermedad como experiencia, descubren que la construcción material y simbólica de las instituciones de salud como ámbito privilegiado de cura fue un proceso extenso y consolidado entrado el siglo XX. Además, muestran que el cuidado de la salud resultaba una preocupación compartida tanto de los vecinos como de las élites gobernantes.

Estas peticiones visualizan, a su vez, concepciones en torno a la salud, la enfermedad y el cuidado, así como sobre el estado de las condiciones sanitarias de la población al calor de la modernización. Algunos casos, además, indican la circulación de concepciones ambientalistas para comprender el funcionamiento y propagación de las enfermedades. Ello no solo habla de los saberes a los que accedían los sectores populares, sino también de la influencia de estos en su movilización y en la construcción de sus demandas.

En igual medida, se expone la inscripción local que tenían las y los actores no diplomados del arte de curar. Si las peticiones posteriores a 1853 se encuadraron bajo los criterios de la ley, en verdad daban cuenta de situaciones que funcionaban de hecho: sanadores y parteras ejercían su oficio en las ciudades y poblados. El pedido de su autorización bajo coyunturas específicas parecía responder más bien al mayor control ansiado por el Estado o los médicos del Consejo. Dicho control, empero, tampoco podía asegurarse en última instancia, bien porque sus funcionarios apoyaban a los actores "ilegales" o bien porque los facultativos autorizados no eran suficientes ni permanecían en ciertas localidades. 
En suma, en este breve recorrido esbozamos algunas líneas de análisis para profundizar la conformación de un conjunto de necesidades y demandas como parte de un acceso a la salud que poco a poco comenzaba a comprenderse - “desde abajo"- como un derecho. El estudio de este tópico - poco explorado regionalmente bajo este enfoque- permitirá reflexionar sobre la configuración histórica de los sentidos sobre las enfermedades, los procesos de cura y los actores legítimos a quienes recurrir. Identificar una serie de problemas comunes a este registro apunta también a comparar casos y observar los "avatares de la medicalización” en sus distintas facetas, así como el proceso de construcción del Estado como espacio polifónico.

\section{Fuentes}

\section{Manuscritas}

Archivo General de la Provincia de Santa Fe, Santa Fe (AGPSF) Gobierno

\section{Impresas}

Provincia de Santa Fe. Registro Oficial (1867-1869). Santa Fe: Imprenta Oficial, s.f. . Registro Oficial (1887). Santa Fe: Imprenta Oficial, s.f.

\section{Bibliografía}

Agostoni, Claudia. "Ofertas médicas, curanderos y la opinión pública: el Niño Fidencio en el México posrevolucionario”. Anuario Colombiano de Historia Social y de la Cultura 45.1 (2018): 215-243. DOI: 10.15446/achsc. v45n1.67557.

Allevi, José Ignacio y Adrián Carbonetti. "Peticiones y prerrogativas. Médicos y boticarios en la corporativización del arte de curar y la conformación del Estado provincial en Santa Fe, Argentina (1857-1903)". Varia Historia 35.69 (2019): 753-786. DOI: 10.1590/0104-87752019000300004.

Armstrong, David. “The Patient's View”. Social Science and Medicine 18.9 (1984): 737-744.

Armus, Diego. "El descubrimiento de la enfermedad como problema social". Nueva historia argentina. Tomo 5. Dir. Mirta Zaida Lobato. Buenos Aires: Editorial Sudamericana, 2000.

. "Historias de enfermos tuberculosos que protestan. Argentina, 19201940”. Avatares de la medicalización en América Latina, 1870-1970. Comp. Diego Armus. Buenos Aires: Lugar Editorial, 2005.

. "Legados y tendencias en la historiografia sobre la enfermedad en América Latina moderna”. Críticas e atuantes. Ciencias sociais e humanas em 
saúde na América Latina. Orgs. Maria Cecília de Souza Minayo y Carlos E. A. Coimbra Jr. Río de Janeiro: Editora Fiocruz, 2005.

Biernat, Carolina. "Jueces, médicos y enfermos: prácticas y sentidos en la construcción social del delito de contagio venéreo en Argentina durante la primera mitad del siglo XX”. História 38 (2019):1-32.DOI: 10.1590/1980-4369e2019050.

Bohoslavsky, Ernesto y Milton Godoy Orellana. Eds. Construcción estatal, orden oligárquico y respuestas sociales (Argentina y Chile, 1840-1930). Buenos Aires: Prometeo Libros / Universidad Nacional de General Sarmiento, 2010.

Bonaudo, Marta. "Hecho jurídico... hecho político. La conflictiva relación entre poder y justicia en la construcción de la República posible. Santa Fe, 1856-1890". Política, cultura y religión. Del antiguo régimen a la formación de los estados nacionales. Homenaje a Reyna Pastor. Coords. María Inés Carzolio y Darío G. Barriera. Rosario: Prohistoria Ediciones, 2005.

. Dir. Nueva historia argentina. Tomo 4. Buenos Aires: Editorial Sudamericana, 1999.

Bonaudo, Marta y Elida Sonzogni. "Las resistencias y demandas ciudadanas frente a las lógicas del mercado y las políticas del Estado (Santa Fe, Argentina, 1890-1912)". América Latina en la Historia Económica 34 (2010): 237-267.

Burke, Peter. Cultura popular en la Europa moderna. Madrid: Alianza Editorial, 2014.

Cervera, Federico Guillermo. Historia de la medicina en Santa Fe. Santa Fe: Colmegna, 1973.

Condrau, Flurin. "The Patient's View Meets the Clinical Gaze”. Social History of Medicine 20.3 (2007): 525-540. DOI: 10.1093/shm/hkm076.

Correa Gómez, María José. “Por haber sanado a muchos y haber matado a varios. Charlatanes, practicantes y curanderos. La justicia y el ejercicio médico ilegal. Chile, 1874-1919”. Delincuentes, policías y justicias. América Latina, siglos XIX y XX. Ed. Daniel Palma Alvarado. Santiago: Ediciones Universidad Alberto Hurtado, 2015.

Darnton, Robert. La gran matanza de gatos y otros episodios en la historia de la cultura francesa. México: Fondo de Cultura Económica, 2002.

Di Liscia, María Silvia. "Reflexiones sobre la 'nueva historia social' de la salud y la enfermedad en Argentina". Historias de salud y enfermedad en América Latina. Eds. Adrián Carbonetti y Ricardo González Leandri. Córdoba: Universidad Nacional de Córdoba, Centro de Estudios Avanzados, 2008.

Di Liscia, María Silvia y Ernesto Bohoslavsky. Eds. Instituciones y formas de control social en América Latina, 1840-1940. Una revisión. Buenos Aires: Prometeo Libros / Universidad Nacional de General Sarmiento / Universidad Nacional de la Pampa, 2005.

Di Meglio, Gabriel. Historia de las clases populares en la Argentina. Desde 1516 hasta 1880. Buenos Aires: Sudamericana, 2012.

Djenderedjian, Julio C. “La colonización agrícola en Argentina, 1850-1900: problemas y desafios de un complejo proceso de cambio productivo en Santa Fe y Entre Ríos”. América Latina en la Historia Económica 30 (2008): 129-157. 
Edler, Flavio C. "De olho no Brasil: a geografia médica e a viagem de Alphonse Rendu”. História, Ciências, Saúde - Manguinhos 8 (2001): 925-943.

Figueiredo, Betânia Gonçalves. A arte de curar. Cirurgiões, médicos, boticários e curandeiros no século XIX em Minas Gerais. Río de Janeiro:Vício de Leitura, 2002.

Fiquepron, Maximiliano Ricardo. "Los vecinos de Buenos Aires ante las epidemias de cólera y fiebre amarilla (1856-1886)”. Quinto Sol 21.3 (2017): 1-22. DOI: $10.19137 /$ qs.v21i3.1230.

. "Lugares, actitudes y momentos durante la peste: representaciones sobre la fiebre amarilla el cólera en la ciudad de Buenos Aires, 18671871”. História, Ciências, Saúde - Manguinhos 25.2 (2018):335-351. DOI: 10.1590/s0104-59702018000200003.

Fleck, Eliane Cristina Deckmann. "Sobre feitiços e ritos. Enfermidade e cura nas reduções jesuítico-guaranis (século 17)". Varia Historia 21.33 (2005): 163-185.

Fradkin, Raúl O. y Gabriel Di Meglio. Comps. Hacer política. La participación popular en el siglo XIX rioplatense. Buenos Aires: Prometeo Libros, 2013.

Foucault, Michel. El nacimiento de la clínica. Una arqueología de la mirada médica. Buenos Aires: Siglo XXI Editores, 2011.

Gallo, Ezequiel. La pampa gringa. La colonización agrícola en Santa Fe (1870-1895). Buenos Aires: Edhasa, 2004.

Palmer, Steven. "La voluntad radiante del Profesor Carbell. Medicina popular y populismo médico en Costa Rica en el decenio de 1930”. Entre médicos y curanderos. Cultura, historia y enfermedad en la América Latina moderna. Ed. Diego Armus. Buenos Aires: Grupo Editorial Norma, 2002.

Pimenta, Tânia Salgado . "Physicians and Surgeons in the early decades of the nineteenth century in Brazil”. Almanack 22 (2019): 88-119. DOI: 10.1590/2236-463320192204.

Pita,Valeria Silvina. “De negociaciones cotidianas y de posibilidades históricas: una aproximación a los intercambios entre médicos y trabajadoras. Buenos Aires, 1870-1940". Anuario de Historia Regional y de las Fronteras 19.2 (2014): 365-390.

Porter, Roy. “The Patient's View: Doing Medical History from Below”. Theory and Society 14.2 (1985): 175-198.

Roldán, Diego P. “La formación de los sectores populares urbanos en la historiografía argentina. Una mirada sobre el núcleo”. Signos Históricos 10.20 (2008): 194-232.

Sedrán, Paula y otros. “Juan P. Quinteros, espiritista. Disputas por los sentidos legítimos del arte de curar. Santa Fe, fines del siglo XIX". Revista de Indias 78.274 (2018): 819-843. DOI: 10.3989/revindias.2018.025.

Shorter, Edward. Doctors and their Patients. A Social History. New York: Simon and Schuster, 1985.

Soprano, Germán. "El Estado en los extremos. Contribuciones de la historiografia hispanocolonial y la antropología de la política al estudio del Estado en el 
siglo XX”. Estudios Sociales del Estado 1.1 (2015): 5-25. DOI: 10.35305/ ese.v1i1.18.

Spivak, Gayatri Chakravorty. ¿Puede hablar el subalterno? Buenos Aires: El Cuenco de Plata, 2011.

Suriano, Juan. Comp. La cuestión social en Argentina, 1870-1943. Buenos Aires: Editorial La Colmena, 2000.

Weber, Beatriz Teixeira. As artes de curar: medicina, religião, magia e positivismo na República Rio-Grandense, 1889-1928. Santa María: Editora da Universidade Federal de Santa Maria, 1999.

. "Espiritismo e Saúde: concepções a partir das práticas numa sociedade kardecista”. Revista Brasileira de História das Religiões 5.15 (2013): 19-46.

Witter, Nikelen Acosta. "Curar como Arte e Ofício: contribuições para um debate historiográfico sobre saúde, doença e cura”. Tempo 19 (2005): 13-25. 